\title{
Gender Difference in Health Condition Among Emirati Adolescent: Role of Environment and Parent Perceptions
}

Praveen Maghelal ( $\nabla$ pmaghelal@gmail.com)

Khalifa University of Science Technology - Masdar City Campus https://orcid.org/0000-0003-0324-9955

Khaled Alawadi

Khalifa University of Science Technology - Abu Dhabi Campus: Khalifa University of Science and Technology

Abeer Wahdain

Khalifa University of Science Technology - Abu Dhabi Campus: Khalifa University of Science and Technology

\section{Research}

Keywords: Obesity, Health Condition, Emirati Adolescents, Parent Perception, United Arab Emirates

Posted Date: June 23rd, 2021

DOI: https://doi.org/10.21203/rs.3.rs-623152/v1

License: () (i) This work is licensed under a Creative Commons Attribution 4.0 International License. Read Full License 


\section{Abstract}

Background: The United Arab Emirates (UAE) is one of the developed nations in the middle-east with the obesity rate among the youth two to three times greater than the international standards. Therefore, this research aims to study the variation of perception of the built environment among Emirati male and female adolescents and their parents. Also, the role of determinants of the health condition of Emirati adolescents is analyzed.

Method: A total of 335 students (aged 14-20) from six schools in the Al Ain region of Abu Dhabi Emirate and 250 parent responses were used to conduct the mean-test of perception of hindrances and multinomial logit of the health condition using the perception, behavior and built environment measures.

Results: Emirati males perceive the built environment factors as barriers more than female adolescents. Parents perceive street-crossing $(p<0.016)$ and sidewalk characteristics $(p<0.020)$ to be more of a hindrance to walking to school than students. Traffic exposure and walkability at home and schools report a significant effect on the health condition of the Emirati adolescents along with the self-reported physical activity. Marginal effect reports sedentary and lowlevels of activity predicts the probability of an Emirati adolescent being not just overweight or obese $(p<0.001)$, but also underweight $(p<0.05)$

Conclusion: Recommendations for parents and school authorities, Abu Dhabi Municipality and Urban Planning department, and to enhance the built environment are discussed. Also recommendation to address both, levels of obesity and being underweight, are discussed.

\section{Background}

The health statistics of the United Arab Emirates (UAE) reports that obesity among children and adolescence in UAE is high and drastically increasing [1]. The obesity rate among Emirate youth is two to three times greater than the international standards [2] and is related to the low levels of physical activity (PA) [3]. In 2016, a study confirmed that the level of PA of UAE children does not reach the required level of PA per day [4]. The lack of PA resulting from the current lifestyle is considered the main reason behind increasing adverse health conditions, including obesity among the UAE population [5].

The 'executive regulation concerning the school transport' by the Abu Dhabi Department of Education and Knowledge (ADEK), restricts students from crossing major roads with a designated speed of more than $40 \mathrm{kmph}$ to reduce exposure to high traffic. Also, the built-environment around the school and homes of the school-going children do not support walking in general. This could hinder student or parent's choice of walking to school and hence reduce opportunities for physical activity. This may lead to a negative perception of the built environment for both the parents and the children as individuals who usually are not engaged in walking have a higher negative perception of the environment [6].

Few studies in the last decade have investigated the determinants of obesity in the UAE or the Emirati population and even less specifically target the adolescent population [7]. Most studies focus on either obesity or overweight and not on the overall health condition among the UAE population [8]. To our knowledge, none of them included parent perception to analyze the overall health of the Emirati adolescents as comprehensively. Additionally, we examine the predicted probabilities of levels of physical activity on health conditions of Emirati adolescent, a rarity in obesity studies.

This study, therefore, examines the perception of the built-environment among Emirati male and female adolescents and check if their perception varies with parent's perception. This study also analyzes the role of determinants of built-environment (both subjective and objective), parent and adolescent perceptions, and constraints (traffic exposure) and level of physical on the health condition of the Emirati adolescents. The outcome of this can provide important implications to enhance the levels of physical activity, improve the health conditions of the Emirati adolescents, and enhance the environment to change the perception of parents and adolescents. It should be noted that this study all adolescents refer to the 'Emirati' adolescents in this study.

\section{Parent-Child Perception of Built-Environment}

The parents-child perception of the built-environment has reported varying results. Some studies suggest the parents often exhibit concerns related to the different factors (demographic, and built environment factors) that usually deter the use of non-motorized transportation modes [9]. Other studies report that parents are more likely to exhibit high levels of confidence regarding their children's capability to navigate the built environment safely [10]. Also, seemingly independent children are often capable of taking care of themselves and can maneuver traffic and the networking routes to reach the intended destination, whether it is school or home [11]. This attitude thus plays a critical role in the parent permitting the child to walk to school or to utilize the inactive means of transportation that is often more secure [12]. Also, gender studies report male children to be more physically active than females [13] and hence several studies focus on improving the health and activities for female children and adolescents [14].

Parental and child safety concerns are likely to be reduced by the creation of safer routes to schools by reducing traffic volume and speed as well as improving the availability and quality of sidewalks in neighborhoods surrounding schools. Integrating strategies that make safer school routes and ease concerns surrounding safety by educating children about walking safely in their neighborhoods have been recommended to encourage walking safe and effective [15].

\section{Walkability and Physical Activity}

Built environment factors such as distance, travel time, safety, urban form and density, land use, and street design (i.e., speed limit, traffic capacity, sidewalk, crosswalk, street connectivity) are related to active transport to school, including distance and route network $[15,16]$.

Neighborhoods with a high score of walkability- high street connectivity and low traffic-, witnessed the increased likeliness of children walking to school and report higher levels of physical activity. Conversely, neighbourhoods that have high connectivity in addition to high traffic volume had children that are less likely to walk and act as a deterrent to achieving the recommended levels of physical activity and negatively impacts the satisfaction and the social capital of the neighborhood [17]. Thus, the context of the home and school environment is essential and needs to accommodate a higher concentration of pedestrians 
[18]. Other built-environment variables such as the land use mix, residential density, and street connectivity are the critical factors for assessing the walkability of a location and can provide insights for design and policy recommendations [19].

\section{Methods}

Study Area

This study was conducted in the Emirate of Abu Dhabi, the capital of UAE and also the largest of the seven emirates as it occupies $87 \%$ of the total area of the UAE. The Emirates of Abu Dhabi consists of three regions: Abu Dhabi-the capital central region, the Al Ain region, and the Western region, as shown in Fig. 1.

Study population

School-going children within the age group of 14-20 years (from 10th to 12th grade) from six schools from Al Ain were selected for this study. ADEK provided the approval to survey school students and their parents in public and private schools for this study, and IRB approval was obtained for human subject research from the institution. Informed consent was obtained from the parents and school children for the study. As public schools in the UAE are not co-ed schools, a pair of boys and girls school in the same district were selected. One private school from one of these districts was included in the study.

Survey Content and Administration

Parents were sent consent forms to request approval to volunteer and let their kids volunteer in the study. Student completed the survey in school while the parents who agreed to participate in the study completed the survey and sent it to the school. The school representatives were educated about the purpose and goals of this study to answer any questions. The survey inquired about the socio-economic, demographic, behavioral, and perception questions. Both the student and parent surveys were translated into Arabic (the local language in UAE) and were administered to the respondents.

Measures

\section{Dependent Variable: Health Condition}

The measure of the Body Mass Index (BMI) based on age and gender specification from the International Obesity Task Force (IOTF) [20] were categorized as underweight, healthy weight, overweight, and obese health condition for students. These categorical measures of health condition were used as the dependent variable for the adolescents. The BMI for the participants was calculated by dividing the weight of each student by square of their height.

Physical Activity Score

The physical activity score was calculated based on student's responses about their active and sedentary behavior. The alpha value of the score was over 0.65 and hence was used further for the analysis. The outcome categories ranged from: Sedentary (1: -5-0); Low Activity (2: 1-6); Moderate Activity (3: 7-13); High Activity (4: 14-20); Vigorous (5: 21-27).

Built-Environment Perceptions

Perception of parent and the adolescent identified their concerns related to the constructs of sidewalk, street, traffic, safety, and appeal of the built environment. The concerns for each of the above constructs were summed to calculate the perception of concerns related to the five built-environment constructs.

Walkability Index

The walkability index for schools and homes was calculated as the sum of intersection density, residential density, and land use mix [21]. The z-score for each variable - residential density, street connectivity, and land use mix was calculated and aggregated for $400 \mathrm{~m}$ from the six schools and residences of individual student using: Walkability Index $(\mathrm{WI})=\mathrm{z}$-score (residential density) $+2^{\star} \mathrm{z}$-score (intersection density) $+\mathrm{z}$-score (Land use mix)

Exposure to Traffic:

The regulation by the ADEK restricts students from crossing major roads with designated speeds of $40 \mathrm{kmph}$ and above. Hence to evaluate the traffic exposure as a measure of speed, we used the the ratio of [length of (Highways + Majorroads)/ length of secondary roads] for the same catchments area as for the walkability index at both origin and destination [18].

\section{Results And Discussion}

Based on the International Obesity Task Force (IOTF) categories, male and female students were grouped into four health categories. About $30 \%$ of females and $40 \%$ of males are either overweight or obese (Table 1). While close to two-third of emirate females were in the normal weight category, only half of their counterparts were in the normal weight category. This suggests male adolescents are at higher risk of various health concerns related to physical inactivity than females. 
Table 1

Health condition based on reported BMI of Emirati

male and female adolescents

\begin{tabular}{|lll|}
\hline Health Code & \multicolumn{2}{l|}{ Emirati Adolescents } \\
\hline & Female & Male \\
\hline 1 - Underweight & $10(7.5 \%)$ & $9(11.1 \%)$ \\
\hline 2 - Normal Weight & $83(62.4 \%)$ & $40(49.4 \%)$ \\
\hline 3 - Overweight & $21(15.8 \%)$ & $8(9.9 \%)$ \\
\hline 4 - Obese & $19(14.3 \%)$ & $24(29.6 \%)$ \\
\hline & $133(62.1 \%)$ & $81(37.9 \%)$ \\
\hline
\end{tabular}

Perception of Male and Female Adolescents

The perception of the built environment was compared for Male and Female adolescents to assess if their perceptions varied from each other. If so, who among both the sex perceived the environment to be less suitable to walk and also if the difference was statistically significant. Of the total 250 respondents, 158 were female respondents, and 92 were male (Table 2). The respondents marked all concerns under each of these built-environment characteristics that they perceived to be a hindrance. Responses indicate, on average, male adolescents perceived higher average concerns than the females, and the differences were statistically significant for all the built-environment constructs. The street crossing concern for the males almost twice as much as the average concerns of female adolescents. We checked if the difference was due to exposure (walking to school) to the environment. The reported average walking for male and females were not significantly different, which indicates that male adolescent reported higher concerns about the built environment.

Table 2

Two sample t-test to test the differences in the perception of built environment varies between male and female.

\begin{tabular}{|lllll|}
\hline $\begin{array}{l}\text { Built-Environment } \\
\text { characteristics }\end{array}$ & $\begin{array}{l}\text { Female } \\
\text { (Obs. 158) }\end{array}$ & $\begin{array}{l}\text { Male } \\
\text { (Obs. 92) }\end{array}$ & t & P value \\
\cline { 2 - 5 } & Mean (SD) & Mean (SD) & & \\
\hline Side walks & $1.39(1.67)$ & $2.35(2.52)$ & -3.24 & 0.000 \\
\hline Street crossing & $2.04(2.16)$ & $4.00(2.65)$ & -6.01 & 0.000 \\
Traffic & $1.68(2.08)$ & $2.58(2.56)$ & -2.84 & 0.003 \\
\hline Safety & $1.98(2.07)$ & $3.08(2.65)$ & -3.43 & 0.000 \\
\hline Appeal & $1.91(1.86)$ & $2.92(2.63)$ & -3.27 & 0.000 \\
\hline
\end{tabular}

Contrary to several studies, male adolescents report higher concerns or negative perception of the built-environment than female adolescents. This negative perception may be mediated because of two reasons. Firstly, male are associated with more sedentary behavior and engage with indoor recreational activities than being involved in outdoor sports. Secondly, males are known to receive their licenses earlier and drive more than their female counterparts. Further studies that can assess the activities of both male and female adolescents using objective measures such as accelerometer can provide more evidence to this posit.

Parent and Adolescent Perceptions

Parent perception of the built-environment was compared with the perception of adolescents (both male and female). On average, the parent perception varied from the children for the sidewalks and the street-crossing (Table 3). The traffic, safety, and appeal of the environment were not significantly different for the parents and adolescents. While parent's perception of the street-crossing reported lower average than the children, sidewalk characteristics were of higher concern for parents in comparison to the children. 
Table 3

Two sample t-test to test the differences in the perception of built environment vary between children and their parents

\begin{tabular}{|lllll|}
\hline $\begin{array}{l}\text { Built-Environment } \\
\text { characteristics }\end{array}$ & $\begin{array}{l}\text { Parents } \\
\text { (Obs. 151) }\end{array}$ & $\begin{array}{l}\text { Children } \\
\text { (Obs. 250) }\end{array}$ & t & P value \\
\cline { 2 - 5 } & Mean (SD) & Mean (SD) & & \\
\hline Side walks & $2.14(1.35)$ & $1.74(2.07)$ & -2.06 & 0.020 \\
\hline Street crossing & $2.25(2.22)$ & $2.76(2.52)$ & 2.15 & 0.016 \\
\hline Traffic & $2.03(2.12)$ & $2.01(2.30)$ & -0.09 & 0.463 \\
\hline Safety & $2.23(2.36)$ & $2.39(2.36)$ & 0.74 & 0.227 \\
\hline Appeal & $2.28(1.97)$ & $2.28(2.23)$ & -0.02 & 0.509 \\
\hline
\end{tabular}

Parent perceptions are generally more negative to let their children walk than their children's perception. Given that, it was surprising to observe that parents reported lesser concerns on average about the street-crossing in comparison to their children. While about $40-50 \%$ of adolescents were concerned about the width of the street with marked crosswalks, only about $30 \%$ of the parents were concerned about the same. The parents preferred the presence of crossing guard while the kids were keen about having a marked pedestrian crossing for them to cross the street.

The Determinant of Adolescent Health Condition

The determinants of the health condition of the adolescents were assessed using four multinomial models (Table 4). The first or the base model assessed the determinants related only to the perception, age, and sex of the adolescents. The second model built on the base with the inclusion of levels of reported physical activity among these adolescents. The third model assessed the impact of the objective measures of walkability index and traffic exposure, while the full model included the parent's perception of the built environment.

While the r-square for the multinomial regression output is changed in log-likelihood from the intercept-only model to the four models, and unlike the linear regression, it cannot be interpreted the same way, higher the r-square value the better is generally accepted for comparison of models [22]. The r-square value improved the predictability of health condition from the base model with the perception of children and their characteristics from seven percent to $40 \%$ in the full model with parent's perception, physical activity levels, and objective measures of the built environment.

While the results of all four models are narrated, for discussion purposes, the full model will be elaborated for its implication on the health conditions of adolescents in UAE. The results from all four models indicate that the odds that adolescents who have higher concerns with street-crossing ( $p<0.05)$ would be underweight was 2.2 times higher than being normal weight. However, the odds that they would be underweight decreased by three times if they were physically active while being overweight or obese were not statistically significant. Also, the odds that the male adolescent would be either underweight or obese increased by 2.5 times and about 20 times, respectively, than their female counterparts $(p<0.05)$.

The levels of physical activity reported similar results across the three models. Results indicate higher the levels of physical activity lesser are the odds that the adolescent would be underweight in comparison to being normal weight. This suggests that physical activity can not only mitigate the chances of overweight or obesity but can help reduce the chances of an adolescent being underweight.

The objective assessment of the built environment reported an interesting relation with the health condition of the adolescents. The exposure to traffic at destination (schools) reduces the odds that adolescents would be overweight by eight times in comparison to being normal weight. However, exposure to traffic at origin (home location) increases the odds by about four times (full model) that adolescents would be overweight or obese in comparison to being normal weight. This indicates, higher exposure to traffic near the adolescent's household tends to negatively impact the health condition of the adolescents, which complements other studies [23]. However, with an increase in exposure to traffic near schools, the odds that adolescents would be negatively impacted reduces. This could be as the exposure is calculated only for the six study schools. Also, opportunities to engage in PA at school may negate the effect of traffic exposure. However, further studies can confirm the postulate to inform transportation policies around the schools in UAE.

Better walkability at origin (homes) decreases the odds of adolescents being obese, while better walkability at destination (school) increases the odds of adolescents being overweight (by twice) or obese (by 13 times) in comparison to being normal weight. Does this indicate, a walkable environment around the schools does not help the health outcomes of the school-going children? While, again, this is contrary to most studies, this is indicative of several factors such as siting of school and policies related to walking around the school (policy restricting students walking on the road with speed higher than $40 \mathrm{kms}$ ). Studies report siting of the school is an important consideration to encourage PA among school-going children [24]. 
Table 4

Multinomial Logistic regression of health condition of Adolescents

\begin{tabular}{|c|c|c|c|c|c|c|c|c|c|c|}
\hline \multirow{2}{*}{$\begin{array}{l}\text { Variables } \\
\text { Base-case: } \\
\text { Normal } \\
\text { Weight }\end{array}$} & \multicolumn{3}{|c|}{$\begin{array}{l}\text { Adolescent Characteristics \& } \\
\text { Perception }\end{array}$} & \multicolumn{3}{|c|}{ Adolescent Physical Activity } & \multicolumn{3}{|c|}{ Objective Built-Environment } & \multirow{2}{*}{$\begin{array}{l}\text { Parent Percep } \\
\text { Underweight }\end{array}$} \\
\hline & Underweight & Overweight & Obese & Underweight & Overweight & Obese & Underweight & Overweight & Obese & \\
\hline Age (Child) & 0.326 & -0.179 & 0.174 & 0.346 & -0.185 & 0.181 & 0.411 & -0.296 & 0.141 & 0.429 \\
\hline Sex (male) & 0.198 & -0.358 & $0.807^{\star \star \star}$ & 0.372 & -0.294 & $0.836^{\star \star \star}$ & 0.863 & -0.363 & $1.399 * \star$ & $2.575^{\star \star}$ \\
\hline $\begin{array}{l}\text { Perception } \\
\text { of sidewalk } \\
\text { (child) }\end{array}$ & 0.113 & 0.104 & 0.090 & 0.121 & 0.104 & 0.089 & -0.032 & 0.160 & 0.068 & 0.109 \\
\hline $\begin{array}{l}\text { Perception } \\
\text { of Street- } \\
\text { Crossing } \\
\text { (child) }\end{array}$ & $0.356^{\star \star \star}$ & 0.057 & -0.005 & $0.360 * \star \star$ & 0.051 & 0.002 & 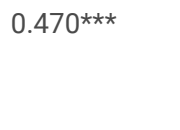 & 0.009 & 0.110 & $2.223^{\star \star}$ \\
\hline $\begin{array}{l}\text { Perception } \\
\text { of Traffic } \\
\text { (child) }\end{array}$ & 0.115 & 0.136 & -0.043 & 0.035 & 0.110 & -0.060 & 0.130 & $0.220^{\mathrm{a}}$ & -0.012 & -0.783 \\
\hline $\begin{array}{l}\text { Perception } \\
\text { of Safety } \\
\text { (child) }\end{array}$ & -0.221 & -0.038 & -0.050 & -0.197 & -0.032 & -0.043 & -0.245 & 0.018 & -0.133 & $-0.828 * \star \star$ \\
\hline $\begin{array}{l}\text { Perception } \\
\text { of Appeal } \\
\text { (child) }\end{array}$ & -0.157 & -0.097 & 0.156 & -0.139 & -0.092 & 0.163 & -0.196 & -0.245 & 0.098 & -1.681 \\
\hline $\begin{array}{l}\text { Levels of } \\
\text { Physical } \\
\text { Activity }\end{array}$ & & & & 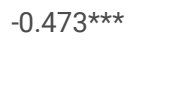 & -0.240 & -0.143 & $-0.635^{\star \star \star}$ & -0.246 & -0.117 & $-3.193^{\star \star}$ \\
\hline $\begin{array}{l}\text { Walkability } \\
\text { Index at } \\
\text { Origin }\end{array}$ & & & & & & & -0.371 & 0.228 & -0.038 & $-2.683^{\star *}$ \\
\hline $\begin{array}{l}\text { Walkability } \\
\text { Index at } \\
\text { Destination }\end{array}$ & & & & & & & 0.299 & 0.635 & 0.391 & -0.252 \\
\hline $\begin{array}{l}\text { Traffic } \\
\text { Exposure } \\
\text { at Origin }\end{array}$ & & & & & & & -0.697 & 1.485 & $1.443^{\star \star \star}$ & -2.449 \\
\hline $\begin{array}{l}\text { Traffic } \\
\text { Exposure } \\
\text { at } \\
\text { Destination }\end{array}$ & & & & & & & -0.739 & $-8.063^{\star \star *}$ & -1.051 & -0.904 \\
\hline $\begin{array}{l}\text { Perception } \\
\text { of Traffic } \\
\text { (parent) }\end{array}$ & & & & & & & & & & $0.435^{\mathrm{a}}$ \\
\hline $\begin{array}{l}\text { Perception } \\
\text { of Street- } \\
\text { Crossing } \\
\text { (parent) }\end{array}$ & & & & & & & & & & 0.054 \\
\hline $\begin{array}{l}\text { Perception } \\
\text { of Safety } \\
\text { (parent) }\end{array}$ & & & & & & & & & & -0.260 \\
\hline $\begin{array}{l}\text { Perception } \\
\text { of Appeal } \\
\text { (parent) }\end{array}$ & & & & & & & & & & 0.458 \\
\hline Obs & 213 & & & 213 & & & 175 & & & 105 \\
\hline $\begin{array}{l}\text { Wald Chi2 } \\
(21)\end{array}$ & 42.10 & & & 58.63 & & & 70.37 & & & 1981.44 \\
\hline Prob > chi2 & 0.0041 & & & 0.0001 & & & 0.0005 & & & 0.000 \\
\hline df & 24 & & & 27 & & & 39 & & & 51 \\
\hline Psuedo R2 & 0.070 & & & 0.081 & & & 0.163 & & & 0.404 \\
\hline AIC & 495.91 & & & 492.502 & & & 409.350 & & & 237.330 \\
\hline $\mathrm{BIC}$ & 575.581 & & & 583.257 & & & 532.777 & & & 372.682 \\
\hline
\end{tabular}




\begin{tabular}{|lllll}
\hline Variables & $\begin{array}{l}\text { Adolescent Characteristics \& } \\
\text { Perception }\end{array}$ & Adolescent Physical Activity & Objective Built-Environment & Parent Percer \\
\hline${ }^{*} \mathrm{p}<0.05,{ }^{* \star \mathrm{p}}<0.01,{ }^{* \star \mathrm{p}}<0.001$ & & \\
\hline
\end{tabular}

Also, higher concerns with sidewalk and traffic increased the odds of adolescents being underweight and obese, respectively. However, higher concerns with safety reduces the odds of the adolescents being underweight in comparison to being normal weight. Surprisingly, parent with higher concerns about streetcrossings was associated with lower odds of their children being overweight $(p<0.05)$ in comparison to being normal weight which is contrary to assumption.

Predicting Probability of Health Condition

The marginal effect of levels of physical activity on health conditions were estimated (Fig. 2). Table 5 reports the probability of an adolescent being underweight is $13.4 \%$ and $6.4 \%$ given that they report sedentary and low levels. It is hence important to propose specific policies to encourage high levels of physical activity not only to deal with overweight ot obesity in adolescents, but also to mitigate negative health impact of being underweight. Also the probability of an adolescent being overweight or obese is significantly related to sedentary, low and moderate levels of physical activity. However, the probability of adolescent being overweight and obeses when engaged is vigorous physical activity is about $13 \%$ and $20 \%$ respectively, while the rest of the predictors are set to their mean values. This could indicate the influence of improper diet, psychological factor or genetic [25]. Although outside the scope of this study, future studies to assess these factors could provide more insight.

Table 5

Marginal effect of activity levels on health conditions

\begin{tabular}{|c|c|c|c|}
\hline \multirow[t]{2}{*}{ Levels of Activity } & \multicolumn{3}{|c|}{ Health Condition of Adolescents } \\
\hline & Underweight & Overweight & Obese \\
\hline Sedentary & $0.134 *(0.063)$ & $0.248^{\star \star \star}(0.076)$ & $0.303^{\star \star \star}(0.087)$ \\
\hline Low & $0.064 *(0.026)$ & $0.106^{\star \star}(0.037)$ & $0.136^{\star \star \star}(0.041)$ \\
\hline Moderate & $0.053(0.029)$ & $0.127^{\star \star}(0.049)$ & $0.232^{\star \star \star}(0.062)$ \\
\hline High & $0.094(0.099)$ & $0.000 \star \star(0.000)$ & $0.073(0.072)$ \\
\hline Vigorous & $0.018(0.018)$ & $0.129 * \star(0.056)$ & $0.199 * \star(0.065)$ \\
\hline \multicolumn{4}{|c|}{${ }^{*} \mathrm{p}<0.05 ; * \star \mathrm{p}<0.01 ; * * * \mathrm{p}<0.001$} \\
\hline
\end{tabular}

\section{Conclusion And Implications}

The United Arab Emirates (UAE) scored an ' $F$ ' on the levels of physical activity and a C- on sedentary behavior in the Global Matrix 3.0 physical activity report card grades for children and youth [26]. This is indicative of an increase in levels of obesity both in the children and adolescents in the UAE. These outcomes of this study have importation implications for the built-environment, health of the adolescents, and encouraging PA.

Implications for Built-Environment

In general, the built environment is perceived to be non-conforming for walking by both females and males. They had major concerns with the constructs of street-crossing and safety of the built environment. Within the construct of street-crossing, the issue of the width of the street, and availability of marked crosswalks was of major concern to the adolescents. Within the construct of safety, the adolescents were concerned about the amount of traffic and unsafe driving behavior on the roads adjoining schools and homes. Street design approaches such as the introduction of "road diets" with curb-cuts at the intersections with textured crosswalks, crossing island, and lane narrowing could improve the perception of safety and concerns related to street-crossing. Studies report such interventions can reduce road crashes by about $6 \%-18.8 \%$ [27].

Both traffic exposure and walkability around the homes of the adolescents have an impact on the health conditions of the adolescents. A better walkable environment with a higher land-use mix and density can encourage more walking [28,29], and reduce the chances of both being underweight and obese in Adolescents. The Department of Urban Planning and Municipalities of Abu Dhabi (ADPM) have suggested implementing the Urban Street Design Manual projects in Al Ain with special consideration to the needs of pedestrians [28]. Implementation of this approach in core residential areas (trip origins) can reduce vehicle speeds, cut-through traffic, and general traffic noise. Additionally, reduction of speed limits on major roads, especially on designated routes for children to walk to and from school could encourage walking within the neighborhood.

In Abu Dhabi, the main concern is about the policies surrounding built environment that make it hard to walk to school [30]. ADEK and ADPM can find transformative strategic plans to promote active commuting to school as the primary mode of transportation. They could follow the example of projects in California that enhanced traffic safety along routes to school (for example, widening of crosswalks and sidewalk improvements), which led to significantly greater walking or biking for children [31].

Implications for Health of Adolescents 
A study by Al-Haddad et al [32] reported that both male and female in UAE tend to be about twice overweight compared to international standards. In this study, obesity and overweight in male adolescents were about $10 \%$ more than female adolescents. Several socio-cultural and behavior factors specific to the region could be attributed to this difference. Culturally, males are the majority of the workforce in the UAE and are engaged in driving more than women. About 75 percent of all trips in the emirate of Abu Dhabi is made by the male [33]. Studies indicate a high correlation of driving behavior and obesity [34], which could be one of the driving factors for higher rates of overweight and obesity among men. A recent study confirmed the high rates of obesity in males in the UAE. It established sedentary behavior as one of the major causes of the obesity epidemic in males [35]. Creating opportunities to engage them in outdoor activities such as soccer and basketball games, a preferred sports activity in the region, within their neighborhood with a directive to engage in outdoor activity should be encouraged among the adolescents and youth in the emirate.

Another less addressed issue with health outcomes is the assessment and impact of underweight [36]. Being a male adolescent is positively associated with being underweight. While significant factors relate to malnutrition and dietary habits, fatigue, emotional, genetic, and psychological factors, and smoking are other factors that can lead to adolescence' underweight health condition. Research suggests using "effective public health programs that can simultaneously promote a healthy lifestyle, improve diet quality, and address both undernutrition and chronic disease" [25]. Health policies that regulate dietary intake both at school and at home need to be promoted. Recently schools in Abu Dhabi restricted the availability of high-calorie food at school. Extending that by providing good dietary plans for students in school can regulate this further and provide the necessary support to curb the issue of underweight in adolescents.

Implications for Enhancing Physical Activity: Planning and Policy

The school environment can provide "quality physical education and supportive environment for a long-lasting healthy and active lifestyle" [37]. Health and physical literacy at schools can provide needed knowledge, motivation, and engagement in physical activity. Control competence allows self-directed structuring and pacing of physical activity, which has shown to be more effective [38]. ADEK policies to actively engage schools to develop control competence approaches for children and adolescents in school can instill PA behaviors that could last until adulthood.

Outside the school environment, the physical environment around the homes of adolescents can provide opportunities for engagement in an active lifestyle. Emirati housing communities lack sizeable open play areas and mixed use development to provide opportunities for after-school activities [39]. Small-area planning approaches such as Transit-Oriented Development (TOD) or Neighborhood Planning Unit (NPU) that incorporate better connectivity, land use mix, and open area planning for Emirati housing neighborhood needs to be proposed. By doing so, the Abu Dhabi Department of Planning and Municipality can enhance the accessibility within these neighbourhood [40]. In addition, "compact" urban fabrics increase opportunities for social interaction and sustain alternate modes of transport such as cycling, walking, and mass transit. Emirati neighborhoods for several decades have been designed as low density developments with no diversity in land use. For that reason, neighborhood design requires an overhaul; new ideologies like compactness, connecitgivty, diversity, and prosimity must be promoted to connect people woth people and people with their destinations.

The street design manual of Abu Dhabi should develop street sections to enhance accessibility and connectivity to schools from residences. A street section that includes wide sidewalk and bike lanes, with minimum lane width and lower speed limits, needs to consider for inclusion in the Abu Dhabi Street Manual. Also, alternative approaches such as pedestrian bridges for students to circumvent major roads with high speed to reduce exposure to high traffic should be incorporated in the design manual. In existing neighborhoods, retrofitting and improving alleys' physical conditions and appearance could also enhance their use and thus support walkability. Recommended physical improvement plans include paving, landscaping, and upgrading lighting to promote walking. Such improvements may be particularly helpful in suburban neighborhoods, where alleys are often unpaved, not utilized, improperly lit, and obstructed by debris and vegetation [41]. Although it's important to improve the environment to increase the physical activity levels, it is also important to increase the awareness of the benefits of physical activity among parents. A recent study stated that to enhance the ability to engage in physical activity, it is important to improve the built environment and raise awareness by educating the parents [42].

The outcomes of this study provide implications to improve the overall health condition for adolescents in Abu Dhabi. While these implications are specific to Abu Dhabi and UAE, major cities in the middle-east have similar socio-cultural, topographic, and demographic characteristics. They can implement similar approaches to enhance the health condition of their local population. However, the policy and planning recommendations are adaptable for all municipalities and schools proactive in improving the built environment and health conditions of school-aged children.

\section{Abbreviations}

UAE - United Arab Emirates

TOD - Transit-Oriented Development

NPU - Neighborhood Planning Unit

ADEK - Abu Dhabi Department of Education and Knowledge

PA - Physical Activity

ADPM - Abu Dhabi Department of Urban Planning and Municipalities

IOTF - International Obesity Task Force

IRB - Institutional Review Board 
$\mathrm{BMI}$ - Body Mass Index

\section{Declarations}

Ethics approval and consent to participate

The study was approved by the Abu Dhabi Department of Education and Knowledge (ADEK). The survey instruments for the school, parent and child were approved by the Khalifa University Institutional Review Board. Consent forms were signed by the representative of each study school. Signed approval was obtained from parents for their own participation and participation of their children in the study. Only students who received approvals from their parents were administered the survey for this study.

Consent for publication

The consent for publication was obtained from all school representative, parents for themselves and their children.

Availability of data and materials

The ADEK approvals do not permit us to share the data with any third party and restricts us from use and distribution of the same without their permission, given the privacy rules in the United Arab Emirates.

Competing interests

The authors declare that they have no competing interests

Funding

This study was conducted without any financial support from any agencies or institutions.

Authors' contributions

PM was responsible for conception, analysis and monitoring of the study. AW was responsible for data collections and approvals. PM, KA and AW analysed and interpreted the data and its implications. PM and KA were responsible for drafting the manuscript. All the authors have read and approved the content of the manuscript.

Acknowledgements

The authors acknowledge the support and advice provided by the Abu Dhabi Department of

Knowledge and Education and the School representative who agreed to participate in the studyand support our data collection.

\section{References}

1. Al Junaibi A, Abdulle A, Sabri S, et al. The prevalence and potential determinants of obesity among school children and adolescents in Abu Dhabi, United Arab Emirates. Int. J. Obes. 2013;37(1):68-74.

2. Al-haddad FH, Little BB, Abdul Ghafoor AG. Childhood obesity in United Arab Emirates schoolchildren: a national study. Ann Hum Biol 2005;32(1):72-9.

3. Ali HI, Ng SW, Zaghloul S, et al. High proportion of 6 to 18-year-old children and adolescents in the United Arab Emirates are not meeting dietary recommendations. Nutr. Res. 2013;33(6):447-56.

4. Paulo MS, Nauman J, Abdulle A, et al. Results from the United Arab Emirates' 2018 report card on physical activity for children and youth. J Phys Activ Health 2018;15(s2):S419-21.

5. Bunc V, Skalská M. Backgrounds of Obesity and Weight Management. Nutr Food Techn 2016;2(2).

6. Lindelöw D, Svensson Å, Sternudd C, Johansson M. What limits the pedestrian? Exploring perceptions of walking in the built environment and in the context of every-day life. J Transp Health 2014;1(4):223-31.

7. Al-haddad FH, Little BB, Abdul Ghafoor AG. Childhood obesity in United Arab Emirates schoolchildren: a national study. Ann Hum Biol 2005;32(1):72-9.

8. Al Junaibi A, Abdulle A, Sabri S, Hag-Ali M, Nagelkerke N. The prevalence and potential determinants of obesity among school children and adolescents in Abu Dhabi, United Arab Emirates. Int. J. Obes. 2013 Jan;37(1):68-74.

9. Oliver M, Badland H, Mavoa S, et al. Environmental and socio-demographic associates of children's active transport to school: a cross-sectional investigation from the URBAN study. Int J Behav Nutr Phys Act 2014;11(1):70.

10. Mitra R, Faulkner GE, Buliung RN, Stone MR. Do parental perceptions of the neighbourhood environment influence children's independent mobility? Evidence from Toronto, Canada. Urb Std 2014;51(16):3401-19.

11. Timperio A, Crawford D, Telford A, Salmon J. Perceptions about the local neighborhood and walking and cycling among children. Prev Med. 2004;38(1):39-47.

12. Grao-Cruces A, Segura-Jiménez V, Conde-Caveda J, García-Cervantes L, Martínez-Gómez D, Keating XD, Castro-Piñero J. The role of school in helping children and adolescents reach the physical activity recommendations: The UP\&DOWN study. J Sch Health. 2019;89(8):612-8.

Page 9/11 
13. Kazim AA, Almarzooqi MS, Karavetian M. The Prevalence and Determents of Eating disorders among Emirati Female Students Aged 14-19 Years in Ajman, UAE. J Food Nutr Disord 6 2017;2:2.

14. Badri MA. School travel modes: factors influencing parental choice in Abu Dhabi. Intl J Edu Eco Dev 2013;4(3):203-18.

15. Trapp GS, Giles-Corti B, Christian HE, et al. Increasing children's physical activity: Individual, social, and environmental factors associated with walking to and from school. Health Educ Behav 2012;39(2):172-82.

16. Maghelal P, Natesan P, Naderi JR, Kweon BS. Investigating the use of virtual reality for pedestrian environments. J Archit Plann Res 2011:104-17.

17. Al-Ali A, Maghelal P, Alawadi K. Assessing Neighborhood Satisfaction and Social Capital in a Multi-Cultural Setting of an Abu Dhabi Neighborhood. Sustain 2020;12(8):3200.

18. Giles-Corti B, Wood G, Pikora T, et al. School site and the potential to walk to school: The impact of street connectivity and traffic exposure in school neighborhoods. Health Place 2011;17(2):545-50.

19. Leslie E, Coffee N, Frank L, et al. Walkability of local communities: using geographic information systems to objectively assess relevant environmental attributes. Health Place 2007;13(1):111-22.

20. Cole TJ, Bellizzi MC, Flegal KM, Dietz WH. Establishing a standard definition for child overweight and obesity worldwide: international survey. BMJ 2000;320(7244):1240.

21. Frank LD, Sallis JF, Saelens BE, et al. The development of a walkability index: application to the Neighborhood Quality of Life Study. Br J Sports Med 2010;44(13):924-33.

22. Heinzl H, Waldhör T, Mittlböck M. Careful use of pseudo R-squared measures in epidemiological studies. Stat Med. 2005 Sep 30;24(18):2867-72.

23. Schlossberg M, Greene J, Phillips PP, et al. School trips: effects of urban form and distance on travel mode. J Am Plann Assoc 2006;72(3):337-46.

24. Yu CY, Zhu X. Planning for safe schools: impacts of school siting and surrounding environments on traffic safety. J Plan Educ Res 2016;36(4):476-86.

25. Doak C, Adair L, Bentley M, Fengying Z, Popkin B. The underweight/overweight household: an exploration of household sociodemographic and dietary factors in China. Pub Health Nutr. 2002;5(1a):215-21.

26. Aubert S, Barnes JD, Abdeta C, et al. Global matrix 3.0 physical activity report card grades for children and youth: results and analysis from 49 countries. J Phys Activ Health 2018;15(s2):S251-73.

27. Pawlovich MD, Li W, Carriquiry A, Welch T. lowa's experience with road diet measures: Use of Bayesian approach to assess impacts on crash frequencies and crash rates. Transp Res Rec 2006;1953(1):163-71.

28. Pimenta AR, Maghelal PK, Alawadi K. Are transit-adjacent developments effective neighborhood design models to help meet the recommended weekly physical activity levels? The case of Abu Dhabi. Int J Sustain Transp 2020;21:1-2.

29. Alawadi K, Benkraouda O. The debate over neighborhood density in Dubai: Between theory and practicality. J Plan Educ Res 2019;39(1):18-34.

30. Badri MA, Ustadi AM, Pierson L, Al Dramaki M. Mode of travel and the decision to allow children to walk or bike to schools-The Abu Dhabi experience. Open J Prev Med. 2012; 2(4):514-527.

31. Boarnet MG, Anderson CL, Day K, et al. Evaluation of the California Safe Routes to School legislation: urban form changes and children's active transportation to school. Am J Prev Med 2005;28(2):134-40.

32. Al-haddad FH, Little BB, Abdul Ghafoor AG. Childhood obesity in United Arab Emirates schoolchildren: a national study. Ann Hum Biol 2005;32(1):72-9..

33. Abu Dhabi Household Travel Diary Survey. Abu Dhabi Department of Transportation, Abu Dhabi UAE 2015.

34. Swanson KC, McCormack GR. The relations between driving behavior, physical activity, and weight status among Canadian adults. J Phys Activ Health 2012;9(3):352-9.

35. Gulf News. UAE: Nearly 70 per cent Emirati male adults under 30 'are obese'. 2019 Jul accessed at https://gulfnews.com/uae/health/uae-nearly-70-percent-emirati-male-adults-under-30-are-obese-1.65102616

36. Uzogara SG. Underweight, the less discussed type of unhealthy weight and its implications: a review. Am J Food Technol Nutr Res 2016;3(5):126.

37. World Health Organization. Global action plan on physical activity 2018-2030: more active people for a healthier world. World Health Organization; 2019.

38. Haible S, Volk C, Demetriou Y, et al. Physical Activity-Related Health Competence, Physical Activity, and Physical Fitness: Analysis of Control Competence for the Self-Directed Exercise of Adolescents. Int J Environ Res Public Health 2020;17(1):39.

39. Alawadi K. A return to the old landscape? Balancing physical planning ideals and cultural constraints in Dubai's residential neighborhoods. J Hous Built Environ 2019;34(1):235-63.

40. Almardood MA, Maghelal P. Enhancing the use of transit in arid regions: Case of Abu Dhabi. Int J Sustain Transp 2019;28:1-4.

41. Scoppa M, Bawazir K, Alawadi K. Walking the superblocks: Street layout efficiency and the sikkak system in Abu Dhabi. Sustain Cities Soc 2018;38:35969.

42. Alawadi K, Benkraouda O. What happened to Abu Dhabi's urbanism? The question of regional integration. J Urban Des 2018;23(3):367-94.

\section{Figure}

Figure 2 is not available with this version.

\section{Figures}




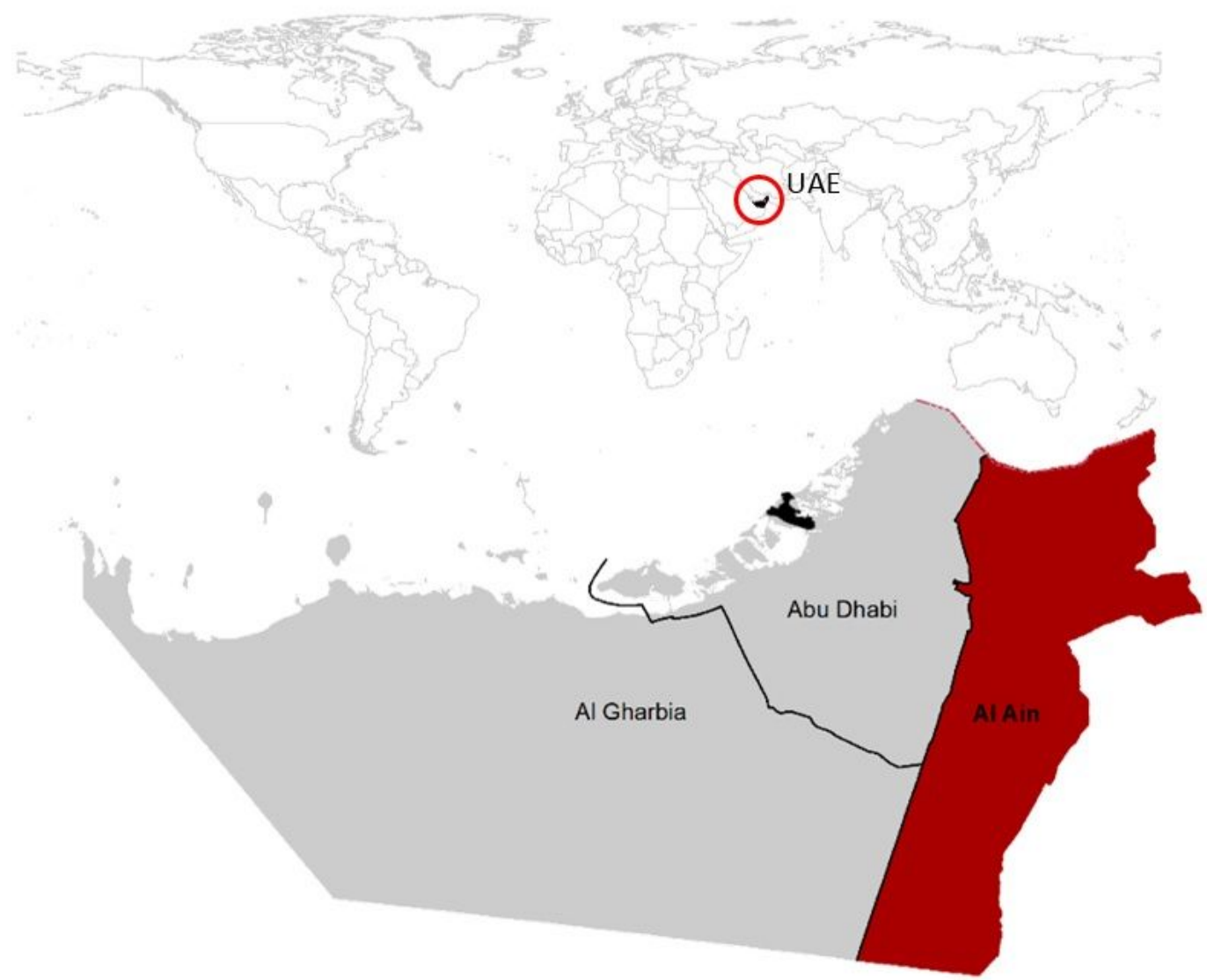

Figure 1

The city of Al Ain is located in the eastern side of the Capital Center and shares its borders with the Sultanate of Oman. Source: Author. Note: The designations employed and the presentation of the material on this map do not imply the expression of any opinion whatsoever on the part of Research Square concerning the legal status of any country, territory, city or area or of its authorities, or concerning the delimitation of its frontiers or boundaries. This map has been provided by the authors. 